\title{
INFLUÊNCIA DO AÇÚCAR NO PROCESSO DE CICATRIZAÇÃO DE INCISÕES CIRÚRGICAS INFECTADAS
}

\author{
Maria do Carmo Lourenço Haddad* \\ Luiz Carlos Bruschi** \\ Eleine Aparecida Penha Martins***
}

HADDAD, M.C.L.; BRUSCHI, L.C.; MARTINS, E.A.P. Influência do açúcar no processo de cicatrização de incisões cirúrgicas infectadas. Rev.latino-am.enfermagem, Ribeirão Preto, v. 8, n. 1, p. 57-65, janeiro 2000.

Trata-se de um estudo experimental, realizado através de análises microbiológicas, que teve por objetivo avaliar a influência do açúcar cristal no processo de cicatrização de incisões cirúrgicas infectadas de 25 pacientes. Nas deiscências foram identificadas as presenças de bactérias gram positivas, gram negativas e fungos. Todos os indivíduos receberam antibioticoterapia sistêmica e tiveram suas incisões tratadas localmente com açúcar cristal, através de 3 curativos diários. A análise estatística demonstrou, através da correlação de Pearson, que o açúcar cristal não influenciou o processo de cicatrização de incisões cirúrgicas infectadas de individuos desnutridos, obesos e com idade avançada.

UNITERMOS: carboidratos, cicatrização de feridas, infecção de ferida pós-operatória, bactérias

\section{INTRODUÇÃO}

As infecções pós-operatórias e hospitalares têm sido um problema desde que surgiram os hospitais, e os esforços para prevenir sua ocorrência e expansão tiveram início centenas de anos atrás, quando foram construídos hospitais de isolamento para pacientes com doenças transmissíveis na tentativa de separar doentes infectados dos demais indivíduos da comunidade (BACELAR et al., 1992).

Com o advento da antibioticoterapia, ocorreu grande euforia nos meios científicos, julgando-se que o problema da infecção estivesse definitivamente resolvido. Contudo, o aparecimento da resistência bacteriana e das superinfecções trouxeram o desencanto pela constatação de que os antibióticos não iriam controlar as infecções por completo (BACELAR et al., 1992).

A infecção da incisão cirúrgica constitui uma parcela significativa no total de todas as infecções hospitalares, sendo considerada a segunda principal causa destas infecções, prolongando o tempo de permanência do paciente, elevando os custos hospitalares, provocando morbidades, problemas psicossociais e incapacidades em alguns casos e morte em outros (SANTOS, 1989).
É importante salientar que a freqüência e a intensidade de cada complicação depende muito do patógeno infectante e do local da ferida cirúrgica, observando-se que metade de todas as complicações pósoperatórias são da incisão cirúrgica e que $50 \%$ destas complicações são de origem infecciosa (ZANON \& NEVES, 1987).

Vários fatores contribuem para aumentar a incidência de infecções pós-operatórias, que podem estar relacionados com as condições prévias do paciente, tais como doenças pré-existentes, desnutrição, idade avançada, obesidade e defesas orgânicas alteradas. Fatores externos como, por exemplo, a técnica cirúrgica adotada e o uso de sondas e drenos também podem contribuir para o aparecimento de infecção na incisão cirúrgica (BACELAR et al., 1992).

Apesar dos progressos obtidos com o desenvolvimento da antibioticoterapia no tratamento das infecções hospitalares, observa-se que as infecções das incisões cirúrgicas continuam sendo motivo de preocupação, principalmente quando há deiscência da ferida operatória.

O processo de cicatrização é universal e após o ferimento ocorre uma seqüência de reações físicas,

\footnotetext{
* Professor Adjunto do Departamento de Enfermagem do Centro de Ciências da Saúde da Universidade Estadual de Londrina e Diretora de Enfermagem do Hospital Universitário Regional do Norte do Paraná

** Professor Associado do Departamento de Histologia da Universidade Estadual de Londrina

*** Professor Auxiliar do Departamento de Enfermagem do Centro de Ciências da Saúde da Universidade Estadual de Londrina e Enfermeira do Hospital Universitário Regional do Norte do Paraná
} 
químicas e biológicas cuja finalidade é reconstituir a continuidade tecidual que foi interrompida. Esta seqüência de reações é idêntica em qualquer tipo de lesão tissular e pode ser dividida em três fases, ou seja, a inflamatória, a fibroblástica e a maturação, que embora sejam distintas, se sobrepõem de tal maneira, que numa delas pode-se observar elementos da fase subseqüente e vice-versa, num processo de envolvimento eminente e dinâmico (MODOLIN \& BEVILACQUA, 1985).

Ressaltamos que um meio ambiente úmido para o processo de cicatrização ocorrer já é conhecido há muito tempo, sendo este o princípio que fundamenta o uso de curativos comercializados pelas indústrias como hidrocolóides, carvão ativado, alginatos porém, em nossa realidade brasileira poucos podem ter acesso à esta tecnologia tornando-se, assim, necessário investigar outras formas de cuidar, na procura de um embasamento científico para práticas alternativas que são de uso popular.

Os cuidados com feridas infectadas são conhecidos desde a antigüidade conforme é relatado no papiro de Smith apud KNUTSON et al. (1981), os cirurgiões egípcios aplicavam açúcar em feridas, desde 1700 a.C. através de combinações de mel e ungüento aplicados diariamente na lesão com ataduras de pano fino.

O mel possui ação bactericida explicada parcialmente pela composição em ácido fórmico, málico e lático, os quais lhe conferem um $\mathrm{pH}$ ácido de aproximadamente 4 , fornecendo um ambiente desfavorável ao desenvolvimento de microrganismo (ALMEIDA, 1949).

Nos países em desenvolvimento, o mel continua sendo usado no tratamento de feridas infectadas. Estudos in vitro realizados com esse produto têm comprovado a sua ação inibidora no crescimento de microrganismos patogênicos, incluindo Streptococcus sp e Staphylococcus coagulase positivo, encontrados em feridas infectadas. Porém, não inibiu certas espécies de Cândida sp (BOSE, 1982).

Outras substâncias que contém açúcar, como o melaço e xaropes, têm sido utilizadas desde tempos remotos por outros povos, como os índios do Peru, Chile e Colômbia, com grande sucesso (KNUTSON et al., 1981; FORREST, 1982; HERSZAGE et al., 1982).

CHIRIFE \& HERSZAGE (1982) e HOLANDA (1984) ressaltaram que, embora substâncias naturais como o mel e o açúcar tenham sido usadas através dos tempos para tratamento local de feridas infectadas, nenhum estudo experimental rigoroso foi feito para elucidar a inibição do crescimento bacteriano e melhora na cicatrização através da utilização desses produtos.

Considerando os aspectos acima levantados, os autores determinaram para esta pesquisa os seguintes objetivos:
1. Avaliar a influência do açúcar cristal no processo de cicatrização de deiscências cirúrgicas infectadas.

2. Realizar estudo microbiológico que identifique as bactérias presentes nas deiscências cirúgicas infectadas tratadas com açúcar.

\section{METODOLOGIA}

A pesquisa foi realizada em um hospital-escola nos anos de 1992 e 1993. Essa instituição mantém convênio com o Sistema Único de Saúde (SUS) e atende a pacientes clínicos e cirúrgicos em todas as especialidades médicas.

A amostra estudada constou de 25 pacientes, com idade variando de 17 a 81 anos, sendo 6 do sexo feminino e 19 do masculino.

O critério utilizado para identificar o número de doentes que fariam parte do estudo foi determinado pela taxa de 5,3\% de supuração cirúrgica, verificada pela Comissão de Controle de Infecção Hospitalar, desse hospital, em 1991 (HOSPITAL UNIVERSITÁRIO REGIONAL DO NORTE DO PARANÁ, 1991). Aplicando-se esse índice sobre o total de 412 cirurgias de médio e grande portes realizadas no Pronto Socorro Cirúrgico, obteve-se um total de 22 pacientes, aproximando o índice para $6 \%$.

Todos os pacientes receberam antibioticoterapia por via sistêmica, conforme prescrição médica.

A avaliação nutricional adotada neste estudo constituiu-se da antropometria e dosagens bioquímicas no soro sangüíneo, que foram realizadas entre o $1^{\circ}$ e o $3^{\circ}$ dia após o diagnóstico da deiscência cirúrgica.

$\mathrm{Na}$ antropometria, foram verificados peso, altura, índice de Quetelet (IQ), prega cutânea triciptal (PCT) e circunferência muscular do braço (CMB).

Os exames bioquímicos realizados foram a albumina ( método do verde de Bromocresol), contagem de linfócitos totais e triptofano livre (método fluorimétrico). Os dados encontrados foram comparados com os padrões de referência, proposto por Blackburn apud BACELAR et al. (1992).

De acordo com a classificação de BLACKBURN (1979), os pacientes foram denominados como desnutridos quando apresentaram 2 índices antropométricos abaixo do $5^{\circ}$ percentil e 1 índice laboratorial alterado. Para os doentes com risco nutricional, ou seja, aqueles nos limites da desnutrição, foram considerados 1 ou 2 índices antropométricos entre $5^{\circ}$ e $10^{\circ}$ percentil e 1 índice laboratorial abaixo do normal.

Segundo o autor acima citado, as medidas antropométricas constam da relação entre peso e altura, que são medidas de proporção corpórea e relativamente 
independente de diferenças genéticas, baseando-se em tamanho absoluto do corpo.

O diagnóstico de deiscência cirúrgica foi feito através do exame físico, considerando o edema local, abertura da incisão, extensão e profundidade da deiscência, presença de tecido necrosado e aspecto da secreção drenada.

A análise microbiológica teve início no mesmo dia e hora da confirmação diagnóstica de deiscência cirúrgica, sendo repetido o procedimento a cada 3 dias até a alta ou óbito do paciente.

A coleta do material foi feita após a limpeza da ferida cirúrgica com solução de soro fisiológico de cloreto de sódio a 0,9\%, utilizando-se "swab" estéril. Em seguida, o material era semeado em meio de cultura de ágar sangue, ágar chocolate, ágar sabourand e dextrose, através de estrias para obtenção de colônias isoladas. Faziam-se também esfregaços em 2 lâminas para avaliação bacterioscópica e a ponta do "swab" era inoculada em caldo de triptose soja (TSB).

As amostras semeadas nos meios ágar e TSB, eram mantidas em estufa por 18 a 24 horas à temperatura de $37^{\circ} \mathrm{C}$ (variando $2^{\circ} \mathrm{C}$ ), com a diferença de que o ágar chocolate era submetido à atmosfera de 5 a $10 \%$ de CO2 As lâminas foram coradas pelo método de gram.

Após o período de incubação, as colônias isoladas que cresceram nos meios agares foram submetidas a coloração de gram e identificadas de acordo com as características morfotintoriais e, em seguida, as bactérias eram semeadas em meios seletivos, utilizando-se o ágar MacConkey para gram negativos e ágar manitol para gram positivo ou em ambos, como foi efetuado na maioria das amostras, para que não ocorressem dúvidas. Para semeadura foi aplicada a técnica de esgotamento, preconizada por ANTUNES (1991).

Terminada essa etapa, as diferentes colônias isoladas a partir do meio MacConkey eram submetidas a triagem bioquímica, ou seja, semeadas em meio EPM (meio desenvolvido na Escola Paulista de Medicina), que permite a observação da fermentação da dextrose, produção da urease, ácido sulfúrico e produção de gás que a bactéria desencadeia. Foram, também, semeadas em meio Mili que permite verificar a mobilidade, descarboxilação da lisina e a produção do indol e por último semeadas no meio citrato de Simmons, constituindo assim a série curta das provas bioquímicas padronizadas no laboratório do hospital.

As colônias isoladas à partir do agar manitol foram submetidas às provas da catalase e coagulase, verificando-se a patogenicidade da bactéria e também à prova da Novobiocina $(5 \mathrm{mg})$ para avaliar a sensibilidade do microrganismo frente ao antimicrobiano.

A técnica adotada para identificar o material semeado no TSB foi idêntica à descrita acima.
Para reconhecimento dos fungos utilizou-se o meio sabourand dextrose (DIFCO), que permaneceu à temperatura ambiente durante um mínimo de 30 dias, sendo efetuada após esse período, uma micoscopia direta a partir do crescimento das colônias.

Os antibiogramas foram realizados para cada bactéria identificada, empregando-se a técnica de difusão de discos em ágar (método BAUER E KIRBY), descrito por ANTUNES (1991). As drogas testadas foram: amicacina, ampicilina, cefalosporina, cefalotina, cefoxitina, cefotoxina, gentamicina, oxacilina, penicilina, sulfametoxazol e trimetoprim, tetraciclina, tobramicina e vancomicina.

Para análise estatística dos resultados obtidos no estudo, adotou-se a correlação de Pearson apud KIRKWOOD (1988).

O tratamento da incisão cirúrgica infectada foi executado de acordo com a técnica recomendada por HADDAD et al. (1983), teve início no dia em que foi detectada a infecção local e procedeu-se da seguinte maneira:

- a limpeza da incisão infectada foi feita com soro fisiológico até a retirada completa das secreções existentes, a seguir, toda a superfície da ferida era recoberta com uma camada de açúcar cristal, até não se visualizarem as bordas da mesma. O local foi ocluído com gazes, que foram fixadas com esparadrapo nas quatro extremidades do curativo;

- nos locais de difícil aderência dos cristais de açúcar, como região perineal, inguinal e proeminências ósseas, utilizou-se uma pasta contendo $98 \%$ de açúcar e $2 \%$ de água destilada;

- o procedimento era repetido 3 vezes ao dia até o surgimento do tecido de granulação e o açúcar não se dissolver nos intervalos dos curativos. A partir deste período, os curativos passaram a ser feitos a cada 12 horas até o aparecimento de tecido epitelial nos bordos da ferida e redução da profundidade da lesão, quando, então, começaram a ser realizados a cada 24 horas até cicatrização total da ferida;

- quando a incisão cirúrgica se apresentava em fase final de cicatrização e o paciente estava em condições de receber alta hospitalar, o mesmo era orientado para fazer seu curativo com açúcar no domicílio e retornar para avaliação ambulatorial após 7 dias;

- os curativos foram feitos pela autora da pesquisa ou por profissional da área de enfermagem por ela treinado e supervisionado.

O processo de cicatrização era acompanhado diariamente, através do registro em protocolo próprio, onde eram anotados o comprimento e a profundidade da lesão, aparecimento e evolução do tecido de granulação, presença de fibrina ou tecido necrosado, aspecto da secreção drenada e outras intercorrências que ocorreram 
com o paciente como, por exemplo, retirada de pontos, ampliação da deiscência ou sutura da mesma.

\section{RESULTADOS E DISCUSSÕES}

Os resultados obtidos foram analisados a partir de uma amostra de 25 pacientes internados na clínica pronto socorro cirúrgico nos anos de 1992 e 1993, que apresentaram infecção na incisão cirúrgica durante o pós-operatório.

Os dados levantados estão apresentados em forma de quadros com valores absolutos e percentuais (Figura 1).

\begin{tabular}{|l|c|c|}
\hline \multicolumn{1}{|c|}{ SEXO } & $\begin{array}{c}\text { N DE } \\
\text { PACENTES }\end{array}$ & P ORCENTAGEM \\
\hline Masculino & 19 & 76 \\
Feminino & 6 & 24 \\
\hline \multicolumn{1}{|c|}{ COR } & & \\
\hline Branca & 22 & 88 \\
Negra & 3 & 12 \\
\hline \multicolumn{1}{|c|}{ IDADE } & & \\
\hline 17 a 29 & 3 & 12 \\
30 a 49 & 7 & 28 \\
50 a 69 & 10 & 40 \\
70 a 81 & 5 & 20 \\
\hline \multicolumn{1}{|c|}{ ESTAD } & & \\
NUTRICIONAL & & \\
\hline Desnutrido grave & 11 & 24 \\
Obeso & 6 & 20 \\
Desnutrido leve & 5 & 12 \\
Eutrófico & 3 & \\
\hline
\end{tabular}

Figura 1 - Quadro de distribuição em número e porcentagem da caracterização dos 25 pacientes quanto ao sexo, cor, idade e avaliação nutricional

Pelo quadro acima, observa-se que a população estudada constitui-se de indivíduos que possuíam risco definido de adquirir infecção no pós-operatório, ou seja, $60 \%$ tinham idade acima de 50 anos e $44 \%$ apresentaram desnutrição grave.

Como todos os pacientes foram operados em regime de urgência, não foi possível adotar uma terapêutica pré-operatória que permitisse melhorar esse quadro nutricional, como é recomendado por FERRAZ (1982); ZANON \& NEVES (1987) e SOUZA \& BARBOSA (1992). Verificou-se também que $24 \%$ desses indivíduos eram obesos, sendo que três apresentaram deiscência cirúrgica completa sem evisceração, e dois não resistiram ao tratamento, ocorrendo o óbito por choque séptico e pneumonia.

MODOLIN \& BEVILACQUA (1985); BACELAR et al. (1992); SOUZA \& BARBOSA (1992) e RODE et al. (1993) afirmam que a obesidade reduz o fluxo sangüíneo na ferida além de sobrecarregar o sistema cardiovascular retardando o processo de cicatrização e, conseqüentemente, a recuperação do paciente, podendo levar à morte.

Os processos de infecção e cicatrização da incisão cirúrgica estão apresentados na Figura 2.

\begin{tabular}{|c|c|c|c|c|c|c|c|c|}
\hline VARIÁVEIS & média & $\begin{array}{l}\text { Desvio } \\
\text { padrão }\end{array}$ & C.V & MIN & Q1 & $\mathrm{Q}^{2}$ & $\mathrm{Q}^{3}$ & MAX \\
\hline $\begin{array}{l}\text { Húmerodo } \\
\text { Pós-operatónio }\end{array}$ & 8,56 & 3,74 & 43,72 & 3 & 6 & 7 & 10 & 17 \\
\hline $\begin{array}{l}\text { Irúcio do Tecido } \\
\text { Gramulação }\end{array}$ & 3,32 & 1,93 & 58,15 & 1 & 2 & 3 & 4 & 10 \\
\hline $\begin{array}{l}\text { Dias de } \\
\text { Tratamerto }\end{array}$ & 16,12 & 11,11 & 68,90 & 5 & 8 & 14 & 19 & 53 \\
\hline $\begin{array}{l}\text { (\%) Redução do } \\
\text { Conprimerto }\end{array}$ & 48,69 & 32,18 & 66,10 & 0 & 25,0 & 50,0 & 66,7 & 100,0 \\
\hline $\begin{array}{l}\text { (\%) Redução de } \\
\text { Profundidade }\end{array}$ & 55,67 & 27,06 & 48,61 & 12,5 & 33,3 & 50,0 & 80,0 & 100,0 \\
\hline
\end{tabular}

* C.V. (coeficiente de variação), MIN (valor mínimo), Q1 (primeiro quartil), Q2 (mediana), Q3 (terceiro quartil) e MAX (valor máximo)

Figura 2 - Quadro dos resultados da estatística descritiva relativa ao processo de infecção e cicatrização da incisão cirúrgica tratada com açúcar

O aparecimento da infecção cirúrgica ocorreu em média, no $8^{\circ}$ dia do pós-operatório, confirmando os dados encontrados por BACELAR et al. (1992); SOUZA \& BARBOSA (1992) e CARRICO et al. (1984), segundo os quais a infecção pode ocorrer em torno do $5^{\circ}$ ao $10^{\circ}$ dia, após a intervenção cirúrgica.

O tecido de granulação na incisão cirúrgica surgiu em média no $3^{\circ}$ dia após o início do tratamento local com açúcar, confirmando os estudos de MODOLIN \& BEVILACQUA (1985).

O tempo médio de tratamento da incisão cirúrgica infectada, a nível hospitalar, foi de 16,12 dias, após esse período, o tratamento foi realizado no domicílio do paciente.

As complicações que apareceram no processo de cicatrização elevou o período de internação, o que também era previsto pela necessidade de se melhorarem as condições gerais dos pacientes e executar uma terapêutica local efetiva que realmente combatesse a infecção. 
O período pós-operatório, em que ocorreu a cicatrização completa, também foi prolongado, em média 53 dias, mas não diferiu muito daquele encontrado por HADDAD et al. (1983), que utilizaram experimentalmente uma pasta de açúcar com $10 \%$ de nitrofurazona no tratamento de feridas infectadas de 31 doentes portadores de câncer quando a cicatrização ocorreu em 45 dias, mesmo nos doentes portadores de diabetes.

MIDDLETON \& SEAL (1985); TANNER et al. (1988); WISEMAN (1989) e SEAL \& MIDDLETON (1991) utilizaram em seus estudos uma pasta contendo açúcar, polietileno e hidrogênio para tratar úlceras de pacientes portadores de hanseníase, escaras de decúbito, deiscência cirúrgica e em imunodeprimidos, obtendo-se bons resultados. Estes autores observaram que, em lesões onde houve exposições de ossos, o tempo de cicatrização foi reduzido de 6 para 3 meses. Destacaram, ainda, a facilidade na aplicação do produto e os custos reduzidos do tratamento.

RAHAL et al. (1984) trataram supuração cirúrgica de 42 doentes com açúcar, observando que o processo de cicatrização ocorreu no prazo de 5 a 30 dias. O autor empregou, também, xarope de solução não estéril de açúcar comum em água a $78 \%$ em abcessos intracavitários, porém não obteve resultados satisfatórios nesses casos.

MEDEIROS et al. (1991) realizaram estudo experimental para avaliar o efeito do açúcar e da solução parenteral no tratamento de feridas infectadas de ratos, verificando que a utilização desses produtos diminuem significativamente o tempo de cicatrização e a contaminação bacteriana, sendo o açúcar ligeiramente mais eficaz.

MARTINEZ et al. (1986) obtiveram cicatrização rápida em úlceras varicosas e deiscências cirúrgicas infectadas nas especialidades de ortopedia, ginecologia e gastroenterologia. Alguns doentes com úlcera varicosa se queixaram de muita dor e foi necessário suspender o curativo com açúcar.

WEISS et al. (1984) realizaram estudo clínico em 30 pacientes portadores de patologias cirúrgicas variadas com infecção de pele e tegumento tratadas exclusivamente com açúcar. Obteve bons resultados em todos os casos independente do tipo de germe e local infectado, além de não ter verificado hiperglicemia em nenhum paciente. Ele destaca a importância de se tomarem medidas pertinentes nos casos de úlceras flebopáticas nas quais a patologia de base deve ser tratada concomitantemente.

HOLANDA et al. (1984) pesquisaram microbiologicamente feridas infectadas de 11 pacientes com deiscência de parede tratadas com açúcar, tendo concluído que o tempo de cicatrização diminui em todos os casos, e que o tecido de granulação surgia, em média, 3 dias após o início do tratamento.

CHIRIFE et al. (1982) observaram que o resultado do tratamento de feridas infectadas com açúcar, em paciente imunologicamente deprimido, é muito bom, contrariando os índices obtidos no presente trabalho, onde o tempo médio de cicatrização foi prolongado e $64 \%$ dos doentes possuíam estado nutricional e imunológico desfavorável.

Neste estudo, mesmo considerando que os pacientes da amostra eram, em sua maioria, desnutridos, obesos, com idade avançada e submetidos à cirurgia de urgência, este resultado foi surpreendente, pois a expectativa era de que o processo de cicatrização fosse acelerado através do tratamento local com açúcar, conforme é relatado por CHIRIFE et al. (1982); RICHA et al. (1982); HOLANDA et al. (1984); RAHAL et al. (1984); WEISS et al. (1984); MARTINEZ et al. (1986) e MEDEIROS et al. (1991).

A análise dos resultados obtidos com a aplicação da correlação de Pearson, descrito por KIRWOOD (1988), também foram surpreendentes, pois embora tenha-se observado, durante o período de internação, uma redução de $48,69 \%$ no comprimento e de $55,67 \%$ na profundidade da incisão, comprovando que o processo de cicatrização estava evoluindo, isto não está correlacionado com os dias de tratamento com açúcar. Julga-se que a cicatrização está intimamente relacionada às condições gerais dos pacientes, que nesta pesquisa encontravam-se bastante alteradas. A infecção cirúrgica dessas incisões eram extensas, com deiscências profundas, portanto com processo de reparação tecidual demorado, constituindo importantes fatores prejudiciais, que não permitiram acelerar o processo de cicatrização, mesmo com a utilização do açúcar. Esses resultados são contrários aos encontrados por CHIRIFE \& HERSZAGE (1982); RICHA et al. (1982); HOLANDA et al. (1984); RAHAL et al. (1984); WEISS et al. (1984); MARTINEZ et al. (1986) e MEDEIROS et al. (1991).

Observou-se, nesse levantamento bibliográfico sobre a utilização do açúcar no tratamento de feridas infectadas, que o perfil metabólico dos pacientes não foi abordado ou considerado nos estudos, embora seja um fator importante na evolução do processo de cicatrização. A metodologia adotada na maioria dos trabalhos foi diversificada, principalmente nas pesquisas realizadas "in vivo".

Nos estudos microbiológicos realizados nas deiscências cirúrgicas infectadas foram identificadas bactérias gram positivas, gram negativas e fungos, conforme demonstra a Figura 3. 


\begin{tabular}{|l|c|c|}
\hline $\begin{array}{c}\text { MICRORGANISMO } \\
\text { ISOLADO }\end{array}$ & $\begin{array}{c}\text { N" DE } \\
\text { PACIENTES }\end{array}$ & $\begin{array}{c}\text { PORCENTAGEM } \\
\%\end{array}$ \\
\hline Escherichia coli & 15 & 60 \\
\hline Staphylococcus aureus & 15 & 60 \\
\hline Enterobacter sp & 8 & 32 \\
\hline Pseudomonas aeruginosa & 7 & 28 \\
\hline Klebsiella sp & 5 & 20 \\
\hline Staphylococcus epidermidis & 4 & 16 \\
\hline Froteus sp & 4 & 16 \\
\hline Streptococcus sp & 3 & 12 \\
\hline Mor ganela morganii & 3 & 12 \\
\hline Staphylococcus saprophyticus & 3 & 12 \\
\hline Cândida sp & 4 & 16 \\
\hline Peptococcus sp & 1 & 4 \\
\hline Penicillium sp & 1 & 4 \\
\hline
\end{tabular}

multiplicação bacteriana na ferida dependem do número inicial do microrganismo invasor e da eficácia dos mecanismos antiinfecciosos locais e sistêmicos do paciente, conforme se observou neste estudo.

Todos os pacientes que receberam alta, encontravam-se com a incisão granulada e sem secreção, porém ainda possuíam contaminação microbiana isolada ou associada, mesmo sendo tratadas com açúcar. Este resultado está parcialmente contrário aos encontrados por BOSE (1982); CHIRIFE \& HERSZAGE (1982); FORREST (1982); HERSZAGE et al. (1982) e RICHA et al. (1982).

HERSZAGE et al. (1982), também encontraram flora bacteriana mista nas incisões cirúrgicas, mas obtiveram rapidamente bons resultados, tratando o local com açúcar. Ressaltaram que o Staphylococcus aureus que permaneceu na lesão era contaminação do revestimento cutâneo.

RAHAL et al. (1984) observaram esses mesmos microrganismos nos pacientes que avaliou, porém todas as culturas se negativaram entre o $2^{\circ}$ e $14^{\circ}$ dia do tratamento com açúcar. Entretanto, não descreveu quais os germes oportunistas que verificou nesta análise e não os considerou como patogênico.

RICHA et al. (1982), em estudo semelhante, e porcentagem dos microrganismos isolados nas incisões cirúrgicas infectadas de 25 pacientes, durante o tratamento com açúcar

O aparecimento destas bactérias nas incisões cirúrgicas deiscentes eram isoladas ou concomitantes, de acordo com o grau de contaminação de cada paciente. Observou-se que os microrganismos se alteravam em cada análise, não sendo possível estabelecer uma correlação entre as condições dos doentes e a flora encontrada.

Neste estudo, observou-se que o Staphylococcus aureus apareceu em $60 \%$ das amostras, sendo considerado ao lado da Escherichia coli como os grandes responsáveis pelo processo infeccioso, confirmando os dados encontrados por ZANON \& NEVES (1987) e ALTEMEIER (1988).

Os outros microrganismos encontrados nestes doentes, tais como o Enterobacter sp, Pseudomonas aeruginosa, Klebsiela $s p$, Proteus $s p$, Streptococcus $s p$ e outros, apareceram com menor freqüência nas infecções cirúrgicas, não só por estarem presentes na flora microbiana do próprio indivíduo, mas também por fazerem parte do "reservatório hospitalar", podendo contaminar as incisões, principalmente aquelas de pacientes debilitados, como é o caso dos presentes nesta amostra.

ZANON \& NEVES (1987) reforçam que a maioria das feridas cirúrgicas são colonizadas, porém, relativamente poucas supuram. A sobrevivência e a relataram que todas as culturas se negativaram no final do tratamento, porém 1 paciente apresentou incisão granulada com a presença de Escherichia coli.

Observou-se nestes trabalhos que os autores adotaram metodologias diferentes e não computaram o Staphylococcus aureus como patogênico. Neste estudo esta bactéria foi considerada patogênica, baseando-se em afirmações de FERRAZ (1982); ZANON \& NEVES (1987); ALTEMEIER (1988) e BACELAR et al. (1992).

Os bons resultados obtidos pelo uso do açúcar no tratamento de feridas, descritos nos trabalhos citados anteriormente, podem ter uma justificativa comum para o efeito bactericida. Estes resultados são explicados através do efeito osmótico desenvolvido pelo açúcar na membrana e parede celular bacteriana.

Segundo CHIRIFE \& HERSZAGE (1982), todos os organismos vivos requerem água para crescer, sendo que esta necessidade pode ser definida em termos de atividade da água (aW), que representa a água disponível para a sobrevivência do microrganismo. O açúcar granulado (sacarose) altera a disponibilidade da água na ferida a níveis suficientes para evitar o crescimento de microrganismos. O Staphylococcus aureus é o germe patogênico mais resistente à baixa atividade da água, portanto, se ele não puder crescer, outras bactérias menos exigentes quanto à $\mathbf{a W}$, tais como Pseudomonas aeruginosa e Escherichia coli, também não crescerão.

Baseando-se nessa teoria, esses autores, testaram o uso do açúcar microbiologicamente "in vitro" 
verificando que a redução da $\mathbf{a W}$ para aproximadamente 0,86 (195g de açúcar para $100 \mathrm{ml}$ de água), produziu uma completa inibição do Staphylococcus aureus, concluindo que o açúcar é um antimicrobiano universal.

FORREST (1982) discorda dos estudos realizados por CHIRIFE \& HERSZAGE (1982), afirmando ser difícil transferir os resultados obtidos em laboratório para a situação clínica. Ressalta que o Staphylococcus aureus é comum em feridas não cirúrgicas infectadas, enquanto que as incisões cirúrgicas são freqüentemente contaminadas com Escherichia coli ou Pseudomonas aeruginosa. Afirma, ainda, que feridas infectadas por Staphylococcus podem, na maioria das vezes, ser tratadas por desbridamento e drenagens sem uso de agentes tópicos. Verificou que a ação do açúcar ainda não está bem estabelecida, embora a maioria dos pesquisadores tenha assumido a ação osmótica como seu principal princípio ativo, através da redução da $\mathbf{a W}$ na ferida. Relata que a melhora nutricional no tecido tem sido apresentada como possível teoria para o seu efeito, e descreve, inclusive, que foi levantada a hipótese da fermentação do açúcar na ferida produzir álcool antisséptico, que porém foi descartada devido ao fato de o açúcar se dissolver no local em 15 minutos, além de que, como o curativo é oclusivo, poderia macerar as bordas da mesma. Concorda que o efeito predominante do açúcar é a ação osmótica, acrescentando que ele não só diminui a $\mathbf{a W}$ para as bactérias, mas também desidrata células epiteliais, macrófagos e fibroblastos nas margens da ferida, reduzindo a migração e divisão das células, potencializando portanto a cicatrização. Apesar de concordar que o açúcar é um tratamento tópico não tóxico, disponível e barato, ele não aceita a hipótese de o açúcar ser um agente antimicrobiano universal, como é proposto pelos pesquisadores citados.

Observou-se que todos os pacientes receberam antibioticoterapia sistêmica de amplo espectro e, mesmo assim, suas lesões permaneceram contaminadas até a alta hospitalar, constatando que o antibiótico é um coadjuvante no tratamento de infecções cirúrgicas infectadas, conforme está descrito por FERRAZ (1982); ZANON \& NEVES (1987) e BACELAR et al. (1992).

\section{CONCLUSÕES}

- O açúcar cristal não influenciou o processo de cicatrização de incisões cirúrgicas infectadas de indivíduos desnutridos, obesos e com idade avançada.

- Os microrganismos encontrados nas incisões cirúrgicas infectadas tratadas com açúcar foram: Staphylococcus aureus, Escherichia coli, Enterobacter $s p$, Staphylococcus epidermides, Proteus sp, Klebsiella $s p$, Pseudomonas aeruginosa, Streptococcus sp, Morganela morganii, Staphylococcus saprophyticus, Cândida sp, Penicillium sp e o Peptococcus sp.

- A remoção mecânica de secreções, fibrina, corpos estranhos e tecidos necrosados, favorecem o desenvolvimento do processo de cicatrização.

- Indivíduos com idade acima de 50 anos, desnutridos e obesos, têm maior probabilidade de desenvolverem infecção na incisão cirúrgica e seu processo de cicatrização é demorado.

\section{CONSIDERAÇÕES FINAIS}

Os resultados encontrados, embora contrários às expectativas iniciais, demonstraram como é importante a realização de pesquisas experimentais, para confirmar e respaldar a prática profissional, corroborando para o estabelecimento da enfermagem como profissão e como ciência.

Recomenda-se a realização de novos estudos, com grupos controle, para comparar a eficácia do açúcar versus curativo úmido e também a abordagem multiprofissional para a prevenção e tratamento das infecções cirúrgicas.

\section{A MICROBIOLOGICAL STUDY ABOUT THE EFFECT OF SUGAR ON THE SCARRING OF INFECTED SURGICAL INCISIONS}

This is an experimental research based on microbiological analysis. Our aim was to evaluate the influence of sugar on the healing process of infected surgical wounds in 25 patients. On the dehiscences, there have been identified gram positive and gram negative bacteria, and fungi as well. Every patient was administered systemic antibiotics and had the wounds treated locally with cristal sugar three times a day. Statistics showed, by Person's correlation, that sugar did not influence on the healing process of infected surgical wounds in undernourished, overweigh and elderly individuals.

KEY WORDS: carbohydrates, cicatri,; surgical wound infection, bacterium 


\section{INFLUENCIA DEL AZÚCAR EN EL PROCESO DE CICATRIZACIÓN DE INSICIONES QUIRÚRGICAS INFECTADAS}

Se trata de un estudio experimental, realizado a través de análisis microbiológicos, que tuvo como objetivo evaluar la influencia del azúcar cristal en el proceso de cicatrización de incisiones quirúrgicas infectadas de 25 pacientes. En las dehiscencias fue identificada la presencia de bacterias "gram positivas", "gram negativas y hongos. Todos los individuos recibieron antibioticoterápia sistémica y tuvieron sus incisiones tratadas localmente con azúcar cristal, a través de tres curaciones diarias. El análisis estadístico mostró, a través de la correlación de Pearson, que el azucar cristal no influenció el proceso de cicatrización de incisiones quirúrgicas infectadas de individuos desnutridos, obesos y con edad evanzada.

TÉRMINOS CLAVES: azúcar, cicatrización, infección quirúrgica, hospitalaria y bactérias

\section{REFERÊNCIAS BIBLIOGRÁFICAS}

01. ALMEIDA, W. O mel na alimentação nacional. Rio de Janeiro: Ministério da Agricultura, 1949. $587 \mathrm{p}$.

02. ALTEMEIER, W.A. Manual de controle de infecção em pacientes cirúrgicos. São Paulo: Roca, 1988. 394p.

03. ANTUNES, G.S. Manual de diagnóstico bacteriológico. Rio Grande do Sul: Universidade Federal do Rio Grande do Sul, 1991. p.11.

04. BACELAR, T.S.; FERREIRA FILHO, H.A.; FERRAZ, E.M. Infecção e cirurgia. In: BARBOSA, H. Controle clínico do paciente cirúrgico. 6. ed. São Paulo: Atheneu, 1992. cap. 11, p. 227-63.

05. BLACKBURN, G.L. Nutrition assessment of the hospitalized patients. Med. Clin. North. Am., n. 63, p. 1103-15, 1979.

06. BOSE, B. Honey or sugar in treatment of infected wounds?. Lancet, v. 1, n. 8278, p. 963, 1982.

07. CARRICO, T.J.; MEHRHOF JUNIOR, A.I.; COHEN, I.K. Biologia da cicatrização dos feridos. Clín.Cir.Am.Norte, Rio de Janeiro, v. 4, p. 763-77, 1984.

08. CHIRIFE, J.; HERSZAGE, L. Sugar for infected wounds. Lancet, v. 2, n. 8290, p. 157, 1982.

09. CHIRIFE, J. et al. Scientific basis for use of granulated sugar in treatment of infected wounds. Lancet, v. 1, n. 8271, p. 560-1, 1982.

10. FERRAZ, E.M. Manual de controle de infecção em cirurgia. São Paulo: EPU, 1982. cap. 5, p. 37-49: Avaliação do risco do paciente à infecção.

11. FORREST, R.D. Sugar in the wound. Lancet, v. 1, n. 8276, p. 861-910, 1982.

12. HADDAD, M. et al. O uso do açúcar nas feridas infectadas. Rev. Enfermagem Moderna, v. 1, n. 1, p. 11-3, 1983.

13. HERSZAGE, L; MONTENEGRO, J.; JOSEPH, A. Treatment of suppurating wounds with applications of succhrose. Nouv. Press. Med., v. 12, p. 940, Mar. 1982.
14. HOLANDA, L.A.C. et al. O açúcar granulado no tratamento das infecções tegumentares. Ceará Médica, v. 6, n. 1-2, p. 36-8, 1984.

15. HOSPITAL UNIVERSITÁRIO REGIONAL DO NORTE DO PARANÁ. Comissão de controle de infecção hospitalar. Relatório Anual. Londrina, 1991. 100p.

16. KIRKWOOD, B.R. Essentials of medical statistics. London: Blackwell Scientific, 1988. p. 234.

17. KNUTSON, R.A. et al. Use of sugar and povidone iodine to enhance healing: five years' experience.

South. Med. J., v. 74, n. 11, p. 1329-35, 1981.

18. MARTINEZ, N.R. et al. O açúcar no tratamento das feridas infectadas. Rev. Bras. Cir., v. 76, n. 1, p. 23-6, 1986.

19. MEDEIROS, A.C. et al. O açúcar e a solução parenteral no tratamento das feridas infectadas. Estudo experimental. Rev. Bras. Cir., v. 81, n. 1, p. 11-4, 1991.

20. MIDDLETON, K.R.; SEAL, D. Sugar as an aid to wound healing. Pharm. J., n. 235, p. 757-8, 1985.

21. MODOLIN, M.; BEVILACQUA, R.G. Cicatrização das feridas: síntese das aquisições recentes. Rev.Bras.Clin.Terap., v. 14, n. 6, p. 55-64, 1985.

22. RAHAL, F.; MIMICA, I.; PEREIRA, V. O açúcar no tratamento local das infecções das feridas operatórias. Rev. Assoc. Méd. Minas Gerais, Belo Horizonte, v. 35, p. 17-8, 1984.

23. RICHA, R.V. et al. El uso clinico del azucar in el tratamiento de las heridas infectadas. Cir. Gen., v. 14, n. 2, p. 175-7, 1982.

24. RODE, H.; BROWN, R.A.; MILLAR, A.J.W. Surgical skin and soft tissue infections. Curr. Op. Inf. Dis., Cape Town, v. 6, p. 683-90, 1993.

25. SANTOS, I. et al. Estudo bacteriológico de infecções pós cirúrgicas no HU/UFPB: participação do enfermeiro. Rev. Bras. Enfermagem, Brasília, v. 42, n. 1/4, p. 72-7, 1989.

26. SEAL, D.V.; MIDDLETON, K. Healing of cavity wounds with sugar. Lancet, v. 338, n. 8766, p. 571-2, Aug. 1991. 
27. SOUZA, J.A.G.; BARBOSA, H. Ferida operatória. In: BARBOSA, H. Controle clínico do paciente cirúrgico. 6. ed. São Paulo: Atheneu, 1992. Cap. 10, p. 205-25.

28. TANNER, A.G. et al. Sucessful treatment of chronically infected wounds with sugar paste.

Eur. J. Clin. Microbiol., v. 7, p. 524-5, 1988.
29. WEISS, R.G. et al. Tratamento da ferida operatória infectada: açúcar uma nova opção. Rev. Amirgs, Porto Alegre, v. 28, n. 4, p. 337-42, 1984.

30. WISEMAN, L.A. Sugar as an aid to wound healing and the treatment of ulcers in leprosy. Lepr.Rev., v. 60, n. 1, p. 67-8, 1989.

31. ZANON, U.; NEVES, J. Infeccões hospitalares: prevenção, diagnóstico e tratamento. Rio de Janeiro: Medsi, 1987. 